\title{
POESIA COMO RECURSO PARA O ENSINO DE ENGENHARIA CIVIL NO PERÍODO DA PANDEMIA DO COVID 19
}

DOI: 10.37702/2175-957X.COBENGE.2021.3367

Maria Aridenise Macena Fontenelle - aridenise.macena@gmail.com

UFERSA MOSSORÓ

Av. Francisco Mota 4492

59626-105 - Mossoró - RN

Maria do Carmo Duarte Freitas - carmemk2@gmail.com

Universidade Federal do Paraná

RUA SCHILLER 555

80050-260 - Curitiba - PR

Resumo: Trata-se de um relato descritivo da prática docente na disciplina de Tecnologia das Construções do curso de Engenharia Civil de uma Universidade Pública de Mossoró-RN, realizado junto aos discentes no período da pandemia do COVID-19 que visa descrever o processo avaliativo utilizando ferramentas da Pedagogia Waldorf. A pesquisa foi realizada através de um estudo de caso se utilizando da técnica de observação assistemática não estruturada e participante das estratégias de ensino-aprendizagem utilizadas na referida disciplina junto a 25 discentes. Ao longo do semestre foram construídas quatro poesias versando sobre os processos construtivos discutidos durante a disciplina como estratégia de avaliação. Foram utilizadas pelos discentes para apresentar o resultado da aprendizagem no processo de ensino e aprendizagem. A partir da experiência, um poeta da cidade de Mossoró acessou as poesias e produziu um poema sobre a situação. Os resultados demonstraram um bom rendimento da turma para além do conhecimento técnico à ativação do sensível.

Palavras-chave: Engenharia civil. Pedagogia Waldorf . Pandemia. Arte 


\section{POESIA COMO RECURSO PARA O ENSINO DE ENGENHARIA CIVIL NO PERÍODO DA PANDEMIA DO COVID 19}

\section{INTRODUÇÃO}

O ensino universitário de engenharia foi estruturado sob padrões que há mais de uma década não atendem às necessidades do mercado profissional. Observou-se ao longo destes últimos anos um crescente movimento pedindo mudanças nos cursos de engenharia com vista a que atenda às demandas sociais.

Disto decorre que no contexto das transformações econômicas e sociais, o CONHECIMENTO, passa a ser mercadoria a ser vendida. As inferências e conclusões muitas vezes divergentes de economistas, empresários, políticos e educadores em torno da formação do engenheiro e de outros profissionais, ainda que conceitualmente justificadas e empiricamente formuladas, apontam, necessariamente, para um consenso em torno da inevitabilidade de um modelo de ensino e formação diferenciado.

Padrão de formação e capacitação tecnológica do engenheiro que se submete a uma ordem econômica (e também ao preenchimento de quadros ocupacionais emergentes das empresas modernas), exigindo dele características cognitivas tais que possam dominar o conhecimento e a tecnologia transformando-as em matéria prima da produção, compreensão, análise, adaptação, associação e organização entre outras, características para, como a própria tecnologia, produzir insumos, produtos e serviços.

Desta forma, o conhecimento tecnológico produzido, difundido e aplicado no ensino de engenharia, tem a tecnologia como requerimento primário, cujo substrato se transforma em produto ou ação pelo trabalho e pela vivência no grupo.

O engenheiro ainda precisa dominar conteúdos de cálculo e física. Mas pelo menos duas situações recentes - a pandemia do novo corona vírus e o avanço das tecnologias educacionais - estão colocando em xeque a maneira mais tradicional de ensiná-los. O resultado disso pode ser uma mudança de paradigma nos cursos superiores de engenharia e, consequentemente, na atuação profissional na área. Fato que pede discussão sobre aplicação diferenciada de estratégias pedagógicas pelos professores que atuam nos cursos de engenharia deste Século XXI.

$\mathrm{Na}$ formação em engenharia, se faz necessário 0 desenvolvimento de competências técnicas, conceituais e relacionais. Fato que a Pedagogia Waldorf traz em sua metodologia de ensino baseada em procedimentos artísticos. Essa pedagogia busca abranger os três veículos de expressão que são: o corpo, a mente e as emoções que correspondem respectivamente as funções do querer, sentir e pensar fundamental para a plena realização do potencial humano. .(BACHEGA, 2009)

$\mathrm{Na}$ Pedagogia Waldorf a quebra de paradigma ocorre na ênfase e valorização da experiência humana, como fonte de vivências que enriquecem o mundo de sensações e sentimentos para dar suporte à vida cognitiva do ser humano. Steiner se inspirou na fenomenologia de Goethe para fundar sua concepção de educação e valorizou o desenvolvimento da sensibilidade como ideal para a formação humana. A educação da sensibilidade é um fator importante tanto no auto cultivo dos professores, quanto na educação das crianças e jovens. O elemento chave na compreensão da educação estética não reside no que se ensina, mas no como. (BACH JUNIOR, 2020.) 
Nas discussões recentes sobre a formação em engenharia se faz urgente à busca por um processo educativo integrado onde para além da educação da técnica, ocorra a educação do corpo. Era urgente a necessidade de uma revolução nos cursos de engenharia que ocorreu com a aprovação, das novas-_Diretrizes Curriculares Nacionais (DCNs) pelo Conselho Nacional de Educação (CNE) em 2019. Trata-se da primeira alteração nas DCNs da área desde 2002. (BRASIL 2019)

Nas Escolas Waldorf o uso de práticas manuais fortalece também o caráter do indivíduo, pois desenvolve a sua força de vontade, criando nela qualidades como a disposição para enfrentar dificuldades e a perseverança. As emoções são trabalhadas por meio da arte: música, canto, desenho, pintura, literatura, teatro, recitação, escultura e cerâmica. Por meio da expressão artística, são dadas muitas oportunidades para o refinamento da sensibilidade, e a harmonização de conflitos na área afetiva e social. Assim, encontra-se neste modelo pedagógico para constituir um escopo para as mudanças propostas pelas DCNs no que diz respeito à formação por competências.

A Visão holística, inovação, empreendedorismo, solução de problemas, cooperação, adoção de perspectivas multidisciplinares e transdisciplinares em sua prática estão entre as características esperadas para os engenheiros do futuro. Assim, arte e atividades práticas são também instrumentos a serviço das matérias acadêmicas. Com a educação integrada de todos os aspectos do seu ser, o ser humano aprende a não dissociar seus pensamentos, sentimentos e ações, tornando-se um adulto e profissional equilibrado e coerente. É a partir dessa necessidade de formação prática e por competências que as metodologias ativas - associadas ao uso de ferramentas tecnológicas - devem ganhar espaço. Com o conteúdo sendo majoritariamente trabalhado fora da sala de aula, o papel do professor, mais do que informar, será estimular o debate e orientar a prática para que o aluno seja o centro do processo de aprendizagem.

Este artigo apresenta o processo avaliativo sobre processos construtivos utilizando ferramentas da Pedagogia Waldorf, sob o formato de poesias, por estudantes na disciplina de Tecnologia das Construções curso de Engenharia Civil de uma Universidade Pública de Mossoró-RN.

\section{PANDEMIA E A APRENDIZAGEM NOS CURSOS DE ENGENHARIA CIVIL}

A pandemia trouxe consigo a necessidade de reorientação do foco do processo de ensino-aprendizagem em direção à aprendizagem ativa. Assim, coube às instituições garantir maior carga horária para visualização da teoria na prática, o que é fundamental para um engenheiro ter boas perspectivas de formação profissional. Antecipando a este evento adverso no mundo, a Confederação Nacional da Indústria (CNI) já havia citado que as mudanças na base curricular nos cursos de engenharia tornarão o ensino no do futuro mais moderno e alinhado às exigências da digitalização.

As DCNs são vistas como uma janela de oportunidades para fazer uma grande revolução na educação dos engenheiros do futuro. Mas a situação de isolamento social provocada pela pandemia do novo coronavírus pode ter um efeito ainda mais transformador. Deste modo, o que havia sido previsto para 2022 no que se refere ao ajuste dos currículos pelas IES, na tentativa de flexibilizar o projeto pedagógico de acordo com a realidade da comunidade teve que ser antecipado.

Muitas tecnologias educacionais utilizadas durante a quarentena vieram para ficar. Afinal, quando aplicadas de maneira planejada e associadas a metodologias ativas de 
aprendizagem, elas evidenciaram o esgotamento do modelo tradicional de ensino e se mostraram imprescindíveis na formação prática e por competências. Isto é, as ferramentas tecnológicas vão ao encontro das necessidades formativas orientadas pelas DCNs. Porquanto, a parceria com a Associação Brasileira de Educação em Engenharia e com o CNE, que previa um documento norteador para a implementação efetiva das DCNs no ensino superior brasileiro através da CNI vem ocorrendo de maneira ainda não oficial mas na pratica docente.

Formados sob a luz de um novo paradigma, os engenheiros, por sua vez, terão condições de transformar a atuação profissional na área. A formação por competências deve agregar habilidades de comunicação e trabalho em equipe, pouco associadas à profissão. A pandemia de Covid-19 explicitou a tendência de ampliar-se a educação a distância (EaD). O que foi feito foi o ensino emergencial online, com soluções interessantes e iniciativas significativas. Observa-se que será será difícil abandonar essa prática, já que a situação anterior não vai existir mais. Terão continuidade após a pandemia. Os alunos irão num futuro próximo para as universidades mais em função da tecnologia, para fazer projetos, desenvolver pesquisas e menos para assistir aulas.

No entanto, para o exercício das práticas docentes é absolutamente necessário conhecer as teorias de aprendizagem, conhecer como aprendem os alunos, saber criar ambientes de aprendizagem, de modo holístico, que incorpore aspectos físicos, sociais, pedagógicos e emocionais. Caberá aos professores reorientar os paradigmas educativos construtivistas centrados no sujeito e em suas experiencias prévias a partir de seus modelos mentais. Isto está presente nas teorias pedagógicas com focos diferenciados quando para: Vigotsky ocorre a interação com outros, Piaget aponta a interação do sujeito com o objeto e Ausubel quando é significativo para o sujeito (FERRACIOLI, 1999; MOREIRA, 2011).

Enfim, a avaliação deve transcender a medição e trabalhar o foco no aluno para que este entenda seus próprio estilo de aprendizagem e sua motivação e interesse. A ideia é que as mudanças transcendam para autoaprendizagem e a melhorias dos processos de aprendizagem adotando modelos baseados na Educação Aberta.

\section{ESTUDO DE CASO}

Trata-se de um relato de experiência como um estudo qualitativo, com caráter exploratório-descritivo na modalidade de um relato da prática docente na disciplina de Tecnologia das Construções do curso de Engenharia Civil de uma Universidade Pública de Mossoró-RN, realizado junto aos discentes no período da pandemia do COVID-19 que visa descrever o processo avaliativo utilizando ferramentas da Pedagogia Waldorf.

A disciplina de Tecnologia das Construções compõe o curso de Engenharia Civil, no oitavo semestre e visa proporcionar aos discentes conhecimentos das etapas de execução dos serviços de uma obra de construção civil com visão dos processos, linguagem técnica e ferramentas básicas para gestão e produção de edificações.

A pesquisa foi realizada através de um estudo de caso se utilizando da técnica de observação assistemática não estruturada e participante das estratégias de ensinoaprendizagem utilizadas na referida disciplina junto a 25 discentes, sujeitos desta pesquisa. As principais estratégias de ensino utilizadas foram o uso de exposição dialogada e construção coletiva de conceitos; estudos de caso; leitura e discussão de textos e artigo científico; trabalhos em grupo utilizando a técnica de seminários dos alunos 
para apresentação estudos de caso e/ou trabalhos práticos realizados bem como visitas técnicas (em formato online).

Optou-se como estratégia de avaliação final, a construção de uma produção técnica e artística (sob o formato livre de poesias) tendo como tema central processos construtivos executados nas obras. Para tanto, os alunos foram divididos em 5 grupos com 5 discentes cada.

Ao final, as poesias produzidas versaram sobre planejamento no processo construtivo, bloco de concreto e telhas recicladas. Apresentaremos as poesias sem identificar os autores, utilizando apenas nomes de emoções para representar os grupos.

Inicialmente as poesias foram analisadas na íntegra. Em seguida, foram sublinhadas as falas individuais, trechos ou transcrições literais do discurso que continham a essência do conteúdo discursivo, chamadas de Expressões-Chave $(\mathrm{ECH})$ dos temas abordados na disciplinas. Nestas foram destacadas as Ideias Centrais (IC), ou seja, nomes ou expressões linguísticas que descreviam de forma precisa e fidedigna o sentido de cada um das poesias analisadas.

As ideias centrais de mesmo sentido encontradas nos poesias em grupo foram unidas, formando uma ideia central síntese a qual abrigava o conjunto das expressõeschave referentes às mesmas pelo poeta mossoroense que elaborou um poema intitulado de Engenharia Humanizada.

\section{RESULTADOS E DISCUSSÕES}

Aprender a aprender, aprender a compreender, aprender a agir por si mesmo num fluxo contínuo, tornou-se condição indispensável para o engenheiro conviver com as mudanças tecnológicas introduzidas no trabalho que tem exigido um aumento nas habilidades cognitivas em detrimento das habilidades mais técnicas e manuais.

Esta dinâmica da disciplina promove uma qualificação diferenciada ao estimular o desenvolvimento da capacidade intelectual de abstração, comunicação, integração (trabalho em equipe), resolução de problemas, inovação, criatividade entre outras. Indicam que os paradigmas de educação e de gestão de pessoal (desenvolvimento de recursos humanos na empresa) devem ser direcionados para a produção desse perfil não apenas como elemento de produtividade, mas como condição de elevação da qualidade de vida do trabalhador com humanização de seus processos.

Sugere-se que sejam ponderadas a qualidade gramatical, criativa e de internalização dos processos no conjunto poético das obras apresentadas a seguir.

\section{Poesias sobre Processos Construtivos}

A Figura 1 mostra a poesia Construindo sonhos produzida pelos grupo de discentes, que foi denominado no texto de Alegria, trazem o conceito para a operacionalização. Destacam a interação entre os profissionais da obra com um objetivo em comum, bem como o foco da Impermeabilização. 
Figura 1: Poesia - Construindo sonhos

Na obra tem de tudo
Doutor, peão e cão pé duro.
Mas não se engane não,
Todos estão ali tem a mesma intenção.
Da fundação ao revestimento
É importante cada momento.
Impermeabilização não pode faltar
Senão água na casa irá entrar.
Construir sonhos é nossa meta
Mas para isso precisamos de regras.
Higiene, organização e companheirismo,
Sem essas coisas não conseguiríamos.
Construir transforma a vida de vários trabalhadores
Com humildade na batalha diária, engolem suas dores
A obra é sempre nossa segunda casa, em nosso coração
Finalizo esse poema homenageando a construção.

Fonte: Grupo Alegria

A Figura 2 mostra a poesia Bloco de concreto produzida pelo grupo de discentes, que foi denominado no texto de Esperança. Após realizar um trabalho da referida disciplina sobre aquisição, recebimento, transporte, armazenamento e aplicação de um material de construção tradicional escreveram a poesia a seguir.

Figura 2: Poesia - Bloco de concreto

\begin{tabular}{|c|}
\hline Quero aqui nesse instante \\
Pra vocês apresentar, \\
O bloco de concreto e o seu processo \\
De como na obra implementar \\
Antes de iniciar \\
A etapa de execução, \\
Conheçamos primeiramente \\
A sua fabricação \\
Realizada por meio de vibração, \\
Seu processo é industrial, \\
Sendo feita a prensagem \\
De todo o seu material \\
Para utilização do bloco, \\
Varia-se conforme a edificação \\
Sendo esse tipo bem requisitado \\
Quando se almeja inovação \\
Apresenta variáveis formatos, \\
O que facilita o ofício, \\
Sendo prático nas instalações \\
Evitando o desperdício.
\end{tabular}

Assenta-se blocos em cada extremidade

Tomando como referência o escantilhão, Formando uma espécie de pirâmide

Em cada extremidade em cada vão.

Estica-se, então, uma linha

No topo dos tijolos assentados,

Do lado da futura face da parede,

Com as pontas presas na parte de baixo.

Com os blocos de concreto inteiros

É iniciada a primeira fiada

Inserindo nas juntas a argamassa

Garantindo que fique bem unificada

Após a primeira, executa-se a segunda fiada

Sendo que com meio bloco deverá ser iniciada

Deixando vaga sua parte mais centrada

Repetindo o processo, até que forme-se a prumada.

Formadas as prumadas

Preenche-se o centro do vão 
Quando chega na obra

Efetua-se logo a checagem

Indicando-se um local correto Para sua estocagem

Obedecendo as normas de segurança Inicia-se, então, a construção

Executando-se cada etapa

Até chegar na vedação

Depois dessa breve apresentação,

Chegamos, enfim, ao nosso objetivo

De demonstrar para vocês,

Do bloco de concreto, o processo construtivo

Sobre o local projetado para as paredes

É feita a demarcação,

Espalhando-se então a argamassa,

Com cuidado e atenção

\section{Tendo sempre o cuidado}

De verificar a nivelação

Elevada a parede até o forro

Falta-se o último complemento

Preencher as juntas com argamassa expansora

Realizando, assim o encunhamento

Depois de pronta a parede

Efetua-se as rebordas e raspagens

Não esquecendo de fazer,

Logo após, a limpagem

Essa poesia chega ao fim

Espero que lhe tenha dado mais uma opção

Que você pense bem, antes de escolher

Um bom bloco para sua vedação

Fonte: Grupo Esperança

Na Figura 3 consta a poesia Telhas recicladas de autoria de um grupo de discentes, que foi denominado no texto de Gratidão, que após realizar um trabalho da referida disciplina sobre aquisição, recebimento, transporte, armazenamento e aplicação de um material de construção inovador escreveram a poesia a seguir.

\section{Figura 3: Poesia - Telhas recicladas}

\begin{abstract}
Escrevemos este poema
Sobre um tema pertinente

Pra tratar de um assunto

Que envolve o meio ambiente

Porque o nosso mundo

Está sendo destruído

E muita coisa envolve

Os processos construtivos
\end{abstract}

Com a utilização crescente de recursos naturais

É importante buscar alternativas

Que minimize os impactos ambientais

Antes que seja tarde demais

A utilização de telhas recicladas Surge como alternativas a serem pensadas

Para diminuir os impactos

Pelas telhas convencionais deixadas

A Ondulite é uma opção

Fabricada a partir da dissolução

De papel. e papelão

Para retirar a celulose, em água quente, no processo de extração

Para eliminar as impurezas

Com o objetivo de fazer uma limpeza
A massa passa por uma centrífuga Até tornar-se lisa

Para retirar os vestígios de água A massa é esticada

Exposta em uma esteira aquecida Até ser aplicada a resina

Após esse processo Para atingirmos sucesso São formadas ondulações

Podendo ser regulares ou não

Depois disso vem a secagem

E logo após a cortagem

E o banho de betume confere resistência,

impermeabilidade e proteção

Para manter a cor e evitar descamação

Finalizando a secagem

O material está pronto para estocagem

Onde o consumidor já pode comprar

E o planeta ajudar

Desde a fabricação

Até a construção

É preciso pensar

E o meio ambiente preservar 
Fonte: Grupo Gratidão

Na Figura 4 consta a poesia Construção civil de autoria de um grupo de discentes, que foi denominado no texto de União Os estudantes escreveram esse poema com base no conhecimento teórico da disciplina de Tecnologia das construções que serve de subsídios para a de orçamento, planejamento e controle de obras.

Figura 4: Poesia - Construção civil

\begin{tabular}{|c|c|}
\hline $\begin{array}{c}\text { Se deseja construir } \\
\text { É preciso planejar } \\
\text { Antes mesmo } \\
\text { Do material comprar } \\
\text { Após essa etapa } \\
\text { Escolha um bom profissional } \\
\text { Se não ele escapa } \\
\text { Sem está na condicional } \\
\text { Não esqueça do seu orçamento } \\
\text { Estimar seus gastos } \\
\text { Se não fica um tormento } \\
\text { E o prejuízo fica vasto } \\
\text { Para tudo melhorar } \\
\text { Tenho um grande auxilio } \\
\text { Faça um cronograma de obras } \\
\text { Será de grande utensilio }\end{array}$ & $\begin{array}{c}\text { Depois de tanto planejamento } \\
\text { Vamos voltar para a obra } \\
\text { Começaremos com a fundação e a laje } \\
\text { Sem muita manobra } \\
\text { Para fechar essa edificação } \\
\text { Vamos usar as paredes } \\
\text { Também conhecidas como vedação } \\
\text { E distribuir as cargas das estruturas como se } \\
\text { promete } \\
\text { Vamos seguindo contente } \\
\text { Proteger a construção } \\
\text { A cobertura vai ficar excelente } \\
\text { Impedindo infiltração } \\
\text { Seguimos com as esquadrias } \\
\text { Com sua melhor qualidade } \\
\text { Sem nenhuma malandria. }\end{array}$ \\
\hline
\end{tabular}

Fonte: Grupo União

A socialização do conhecimento sobre o projeto tocou um poeta da cidade de Mossoró, Mario Neves. O poeta ao saber da escrita de poesias por estudantes de engenharia e escreveu um poema que denominou de Engenharia Humanizada que é mostrado na figura 5.

Figura 5: Poesia - Engenharia Humanizada

\section{Coisa boa está}

Acontecer,

Ver ciências exatas com humanas se desenvolver.

Do trabalho de muita exatidão com cálculos

matemáticos,

vem a poesia

que alivia alma

e humaniza com paixão que

Nasce do fundo

do coração.

Que maravilhoso ver, a razão e o

Coração juntos,

com o cálculo e

a poesia construir o mundo novo como se fosse duas belas harmonias.

Fonte: Mario Neves - Poeta Mossoroense 
Os achados sinalizam que a união do método de ensino on-line, por meio da interação de atividades artística propostas Pedagogia Waldorf, revela-se uma estratégia eficiente para alcance dos objetivos educacionais. Portanto, o uso de estratégias avaliativas holística, que demandem solução de problemas, cooperação, adoção de perspectivas multidisciplinares e transdisciplinares podem ser considerados uma ferramenta complementar ao ensino em engenharia.

\section{CONSIDERAÇÕES FINAIS}

O estudo possibilitou observar que o ensino da arte em algumas aulas no curso de engenharia civil no período da Pandemia, conforme relato dos alunos possibilitou mais leveza, relaxamento e tranquilidade no processo de ensino e aprendizagem.

Como observador da atividade artística realizada pelos discentes, o docente concorda com Steiner quando afirma que esse tipo de prática proporciona sentido para compreender também com o intelecto e de permear também como o senso de dever aquilo que o indivíduo aprendeu a ver na arte como o belo e o humano puramente livre.

Finalmente, a docente da disciplina explora no processo de aprendizagem o conhecimento acumulado sobre a natureza das capacidades cognitivas humanas percepção, memória, raciocínio, conhecimento e representação mental, aprendizagem, linguagem e comunicação, etc. A experiência relatada demonstra que foi rompido os formalismos do ensino tradicional e a estrutura linear e compartimentalizada dos programas de ensino em engenharia que mais privilegia a aprendizagem da técnica subestimando suas implicações.

As produções técnicas e artísticas dos estudantes da disciplina Tecnologia das Construções do curso de Engenharia Civil da UFERSA mostra que a sensibilidade pode ser ativada.

\section{Agradecimentos}

Aos estudantes pela produção técnica artística.

\section{REFERÊNCIAS}

BACH JUNIOR, Jonas. $O$ autocultivo e a educação da sensibilidade na pedagogia waldorf. EccoS - Rev. Cient., São Paulo, n. 53, p. 1-16, e16638, abr./jun. 2020.

BACHEGA, César Augusto. Pedagogia Waldorf, um olhar diferente à educação. An. Sciencult, v.1, n.1, Paranaíba, 2009. P. 360-369.

BRASIL. Resolução CNE/CES no 2, de 24 de abril de 2019 - Institui as Diretrizes Curriculares Nacionais do Curso de Graduação em Engenharia. 2019.

BRESSIANI, L. A utilização da andragogia em cursos de capacitação na construção civil. 2016. 
FERRACIOLI, L. Aprendizagem, desenvolvimento e conhecimento na obra de Jean Piaget: uma análise do processo de ensino-aprendizagem em Ciências. R. bras. Est. pedag. Brasília, v. 80, n. 194, p. 5-18, jan./abr. 1999.

KOCHHANN, Luiz Eduardo. Como a pandemia impôs um novo futuro aos cursos de Engenharia. 27 de maio de 2020. https://desafiosdaeducacao.grupoa.com.br/futurocursos-engenharia/ Acessado em 09 de agosto de 2020.

LANZ, Rudolf. A pedagogia Waldorf: caminho para um ensino mais humano. 6. ed. São Paulo: Antroposófica, 1998.

MOREIRA, M. A. Teorias de aprendizagem. 2. ed. São Paulo: EPU, 2011.

NASCIMENTO, C. R. S. D. A produção de poesia popular como prática pedagógica inovadora: um estudo de caso. 2015.

ROMANELLI, Rosely Aparecida. A arte e o desenvolvimento cognitivo Um estudo sobre os procedimentos artísticos aplicados ao ensino em uma escola Wladorf. Tese de Doutorado. Faculdade de Educação (FE) da Universidade de São Paulo.274p. 2008.

SANTOS, W. S. Andragogia e a educação de idosos, jovens e adultos. Alumni-Revista Discente da UNIABEU-ISSN 2318-3985, v. 4, n. 7, p. 38-47, 2016. ISSN 2318-3985.

\title{
POETRY IN THE TEACHING OF CIVIL ENGINEERING IN THE COVID PANDEMIC PERIOD 19
}

\begin{abstract}
This is a descriptive report of teaching practice in the discipline of Construction Technology in the Civil Engineering course of a Public University in Mossoró-RN, carried out with students during the pandemic period of COVID-19, which aims to describe the evaluation process using tools of Waldorf Education. The research was carried out through a case study using the unstructured unsystematic observation technique and participating in the teaching-learning strategies used in that discipline with 27 students. Throughout the semester, four poems were built on the construction processes discussed during the course as an evaluation strategy. were used by the students to present the learning result in the teaching and learning process. From the experience, a poet from the city of Mossoró accessed the poetry and produced a poem about the situation. The results demonstrated a good performance of the class beyond the technical knowledge to the activation of the sensitive
\end{abstract}

Keywords: Civil engineering, Pedagogy Waldorf . Pandemia. Art. 